\title{
Knowledge, attitudes and practices of breast feeding among lactating mothers in a tertiary care hospital in Dakshina Kannada district: a cross sectional survey
}

\author{
Pramodha M. S., Nikita Pitty*, Chaitra S.
}

Department of Obstetrics and Gynecology, AJ institute of Medical Sciences and Research Centre, Mangalore, India

Received: 28 May 2020

Accepted: 06 July 2020

*Correspondence:

Dr. Nikita Pitty,

E-mail: nikitapitty@gmail.com

Copyright: ( ) the author(s), publisher and licensee Medip Academy. This is an open-access article distributed under the terms of the Creative Commons Attribution Non-Commercial License, which permits unrestricted non-commercial use, distribution, and reproduction in any medium, provided the original work is properly cited.

\begin{abstract}
Background: Breastfeeding plays a crucial role in the general health and wellbeing of infants. However, this fact has been made to look inconsequential due to various misconceptions and lack of adequate knowledge among lactating mothers. The aim of this study was to assess the knowledge, attitudes and practices of breastfeeding among postnatal women in Dakshinakannada district of Karnataka, India. The objective was to educate them and encourage breastfeeding.

Methods: This study is a cross-sectional survey conducted during a period of 2 months from November to January 2019 among 80 postnatal mothers regarding their KAP of breastfeeding. A questionnaire was designed from FAO guidelines for assessing nutrition-related knowledge, attitudes and practices manual and The Iowa Infant Feeding Attitudes. The data was collected by a single interviewer, collaborated into a 3-point Likert scale and analyzed using descriptive statistics.

Results: The study shows that $81.25 \%$ of the mothers had good knowledge regarding breastfeeding, but the alarming finding was that $46.6 \%$ of them had a neutral attitude towards it.

Conclusions: The study showed that there is significant possibility for enhancing breastfeeding practices among lactating mothers by simple provision of supportive prenatal and postnatal counselling. The role played by healthcare workers in this context would be very imperative to accomplish millennium development goals of reducing infant mortality.
\end{abstract}

Keywords: Attitude, Breastmilk, Colostrum, Exclusive breastfeeding, Formula feeds, Healthcare workers, Knowledge

\section{INTRODUCTION}

Breastfeeding is acknowledged extensively as the means of providing infants with paramount source of nutrition during the first 6 months of life. ${ }^{1}$ Breastfeeding has constructive short- and long-term health benefits for both mother and baby. It helps to delay fertility, lose weight gained during pregnancy, lowers risk of breast and ovarian cancer, diminishes risk of postpartum haemorrhage, reduces risk of postpartum depression and improves relationship between mother and baby.
Breastfeeding reduces new-borns risks of developing severe lower respiratory tract infections, sudden infant death syndrome, gastroenteritis, acute otitis media, asthma, type 1 and 2 diabetes and childhood obesity. ${ }^{2}$ Breast milk has vital fatty acids that aid infants' brain development and may increase infants' cognitive skills. Several studies have shown the positive association between breastfed infants and their higher intelligence test scores. $^{3}$ Infant and young child feeding 2006 guidelines suggest an early initiation of breastfeeds (preferably within one hour of birth), exclusive 
breastfeeding for the first six months of life(not giving any other food including water), judicious introduction of complementary foods while continuing breastfeeding after 6 months of age, up to 2 years or beyond and also during and after acute illness.

In India, prevalence of exclusive breastfeeding is $54.9 \%$ and early initiation of breastfeeding is less than $41.6 \%$ which is far from the desired level. Also, infant mortality rate in India as of 2019 has been 30.294 deaths per 1000 live births. Lack of knowledge, ignorance, detrimental socio-cultural ideas and misconceptions prevailing in the society tend to influence breastfeeding performances of the mothers. In a developing country like ours, very few women are familiar about breastfeeding practices and the main source of information to them is through family and friends. ${ }^{4}$ This is seldom sufficient. ${ }^{5}$ This poor knowledge and downbeat attitude may negatively influence breastfeeding practices. Hence, it becomes indispensable for the lactating mother to receive adequate knowledge and maintain a positive attitude right from early pregnancy, to practice breastfeeding as per recommendations to offer utmost benefits to her newborn.

This study is aimed at assessing the knowledge, attitude and practices towards breastfeeding among postnatal mothers in AJ Institute of Medical Sciences-a tertiary care hospital in Dakshinakannada District. It could thus facilitate to recommend any potential interventions that could overcome the statement of problem.

\section{METHODS}

This a cross-sectional survey carried out in the department of obstetrics and gynecology at AJ Institute of Medical Sciences and Research Institute among mothers in postnatal ward for a period of 2 months. An informed written consent was taken from each of the participants after obtaining institutional ethical clearance. A total of 80 postnatal mothers fulfilling the selection criteria were included in the study.

\section{Questionnaire}

A questionnaire, adapted from the Food and Agriculture Organization of the United Nations guidelines for assessing nutrition-related knowledge, attitudes and practices manual and the Iowa infant feeding attitudes scale (IIFAS) was structured. It was pretested on 10 women for precision, validity and easiness of data collection.

- The questionnaire solicited data on demographic and socioeconomic characteristics of the lactating mother.

- To assess the knowledge of the patient with respect to breastfeeding 15 questions were constructed. The responses of the mothers were obtained in terms of knows/does not know/variable for the different statements. A knowledge score was generated for each mother based on the number of questions answered correctly.

- To gauge the patient attitude regarding it 15 questions were framed as per Iowa infant feeding attitudes scale. Half of the questions were negatively worded (i.e. 1, 2, 4, 6, 8, 10, 13, and 15). The responses were obtained on a 5-point Likert scale from strongly disagree to strongly agree and results were finally sorted into agree/disagree/neutral. The mothers were then grouped into either positive attitude to breastfeeding, neutral or positive attitude to formula feeds based on their responses.

- To evaluate the practices of the mothers with respect to breastfeeding 7 questions were structured like prelacteals, colostrum feeding, time of feeding, duration of exclusive breastfeeding, usage of galactagogues etc. This was followed by 6 questions to estimate the correctness of the breastfeeding technique followed.

The data was collected by a single interviewer after explaining the questions in the local language-Kannada and responses were collaborated into 3-point Likert scale for analysis. Collected data was entered into Microsoft excel and analysed using percentages. All mothers who were interviewed were given health education regarding the significance, methods and advantages of breastfeeding.

\section{Inclusion criteria}

- Mothers of healthy infants aged above 18 years

- Delivered between 37 and 42 gestation weeks

- No major birth defects such as congenital heart disease, cleft lip/cleft palate and Downs syndrome

- Who volunteered to participate.

\section{Exclusion criteria}

- Mothers with active chronic diseases like tuberculosis, etc. or medical conditions where breastfeeding was not advised

- Mothers on medications in which breastfeeding was contraindicated

- Mothers of preterm babies,

- Multiple gestations

- Babies with galactosemia, lactose intolerance.

\section{RESULTS}

The study was done in a total of 80 postnatal mothers. The results were analysed according to the following parameters.

\section{Sociodemographic details of the mother}

The age of mothers ranged between 20 and 35 years. The youngest participant was 20 years old. An elderly 
primigravida, aged 35 years, was also included. The proportion of the religions of the mothers surveyed almost corresponded to the distribution within the population. While a small section of the mothers had received only informal education, $43.75 \%$ had been educated beyond middle school. Most of the women were unemployed and were available by the side of the baby throughout the day.

Table 1: Sociodemographic details of the mother.

\begin{tabular}{|c|c|c|}
\hline Socio-demographic details & $\begin{array}{l}\text { Number } \\
\text { of cases }\end{array}$ & Percentage \\
\hline \multicolumn{3}{|l|}{ Age range } \\
\hline $20-25$ years & 35 & $43.75 \%$ \\
\hline 26-30 years & 40 & $50 \%$ \\
\hline$>30$ years & 5 & $6.25 \%$ \\
\hline \multicolumn{3}{|l|}{ Religion } \\
\hline Hindu & 45 & $56.25 \%$ \\
\hline Muslim & 33 & $41.25 \%$ \\
\hline Christian & 5 & $2.5 \%$ \\
\hline Others & 0 & $0 \%$ \\
\hline \multicolumn{3}{|l|}{ Educational status } \\
\hline Informal education & 15 & $18 \%$ \\
\hline Primary school & 20 & $25 \%$ \\
\hline Middle school & 10 & $12.5 \%$ \\
\hline High school & 20 & $25 \%$ \\
\hline Intermediate/diploma & 8 & $10 \%$ \\
\hline Graduate & 6 & $7.5 \%$ \\
\hline Post graduate & 1 & $1.25 \%$ \\
\hline \multicolumn{3}{|l|}{ Employment status } \\
\hline Unemployed & 76 & $95 \%$ \\
\hline Employed & 4 & $5 \%$ \\
\hline \multicolumn{3}{|l|}{ Socioeconomic status } \\
\hline Class 1 & 3 & $3.75 \%$ \\
\hline Class 2 & 6 & $7.5 \%$ \\
\hline Class 3 & 29 & $36.25 \%$ \\
\hline Class 4 & 35 & $43.75 \%$ \\
\hline Class 5 & 7 & $8.75 \%$ \\
\hline \multicolumn{3}{|l|}{ BMI- nutritional status } \\
\hline Under weight & 15 & $18.75 \%$ \\
\hline Normal & 39 & $48.75 \%$ \\
\hline Overweight & 24 & $30 \%$ \\
\hline Obese & 2 & $2.5 \%$ \\
\hline Extremely obese & 0 & $0 \%$ \\
\hline \multicolumn{3}{|l|}{ Parity index } \\
\hline Primigravida & 32 & $40 \%$ \\
\hline Multigravida & 48 & $60 \%$ \\
\hline \multicolumn{3}{|l|}{ Cases } \\
\hline Booked & 78 & $97.5 \%$ \\
\hline Unbooked & 2 & $2.5 \%$ \\
\hline
\end{tabular}

The mothers were categorized according to modified BG Prasad classification as they belonged to both rural and urban backgrounds. It was noticed that majority of the mothers belonged to class 4- upper middle class. Nutritional status was assessed by pre-pregnancy weights of mothers and it was noted that $48.75 \%$ had normal BMI and none was morbidly obese; $40 \%$ of the mothers in the study were primiparas and $97.5 \%$ of them had their regular antenatal check-ups at study hospital (Table 1).

Table 2: Mode of delivery.

\begin{tabular}{|lll|}
\hline Mode of delivery & $\begin{array}{l}\text { Number of } \\
\text { cases }\end{array}$ & Percentage \\
\hline Vaginal delivery & 42 & 52.5 \\
\hline Caesarean section & 38 & 47.5 \\
\hline Instrumental delivery & 0 & 0 \\
\hline
\end{tabular}

\section{Intrapartum}

\section{Mode of delivery}

It was noted that $52.5 \%$ mothers had vaginal delivery and $47.5 \%$ underwent a caesarean section (Table 2).

\section{Indication for C-section}

The table revealed fetal distress, failed induction of labour and previous 2 caesarean sections to be chief indications for caesarean section (Table 3).

Table 3: Indications for LSCS in mothers in study.

\begin{tabular}{|l|ll|}
\hline Indication & $\begin{array}{l}\text { Number } \\
\text { of cases }\end{array}$ & Percentage \\
\hline Previous 2 LSCS & 10 & $23.8 \%$ \\
\hline Cephalo-pelvic disproportion & 3 & $7.14 \%$ \\
\hline Fetal distress & 11 & $26.1 \%$ \\
\hline Failed induction & 10 & $23.8 \%$ \\
\hline Malpresentation & 2 & $4.7 \%$ \\
\hline Medical emergencies & 6 & $14.28 \%$ \\
\hline
\end{tabular}

\section{Immediate neonatal outcome}

It can be seen that $57.5 \%$ mothers had healthy new-borns and $25 \%$ had Hyperbilirubinemia needing phototherapy (Table 4).

Table 4: Immediate neonatal outcomes.

\begin{tabular}{|lll|}
\hline Outcome & Number of cases & Percentage \\
\hline IUGR/LBW & 8 & $10 \%$ \\
\hline Birth asphyxia & 0 & $0 \%$ \\
\hline Hyperbilirubinemia & 20 & $25 \%$ \\
\hline Sepsis & 2 & $2.5 \%$ \\
\hline $\begin{array}{l}\text { Meconium aspiration } \\
\text { syndrome }\end{array}$ & 4 & $5 \%$ \\
\hline Healthy new-borns & 46 & $57.5 \%$ \\
\hline
\end{tabular}

\section{Postpartum}

Period of separation of the mothers from their new-borns - The study showed that $78 \%$ of the new-borns were 
roomed in with their mothers at or within 1 hour of the delivery (Table 5).

Table 5: Period of separation of the mothers from their new-borns.

\begin{tabular}{|lll|}
\hline $\begin{array}{l}\text { Duration of } \\
\text { separation }\end{array}$ & Number of cases & Percentage \\
\hline Less than 1 hour & 16 & $20 \%$ \\
\hline 1 hours & 22 & $27.5 \%$ \\
\hline 2 hours & 23 & $28.75 \%$ \\
\hline $3-7$ hours & 13 & $16.25 \%$ \\
\hline$>7$ hours & 6 & $7.5 \%$ \\
\hline
\end{tabular}

Source of information regarding breastfeeding - health advices and information that the mothers received were mainly from their family and friends. It is significant to note that the role played by health personnel was a mere $3.75 \%$ (Table 6 ).

\section{Knowledge about breast feeding}

It was found that $95 \%-97 \%$ of mothers seem to have good knowledge about colostrum and its significance, $80 \%$ were aware about the benefits of exclusive breastfeeding and $80 \%-91 \%$ of the mothers knew to a good extent the techniques of breastfeeding. It can also be noted that the measures to hygienic breastfeeding was known to $75 \%$ of the mothers. It was seen that $60 \%$ of the mothers were familiar with expressed breastfeeds, the techniques and standards of its storage and usage. Only $36.25 \%$ knew that they could approach healthcare professionals regarding breastfeeding difficulties and minor baby illnesses related to baby nutrition (Table 7).

Each mother was given a knowledge-score based on the number of correct answers given by them $-81.25 \%$ of the study mothers seemed to have relatively good knowledge regarding breastfeeding (Table 8 ).

\section{Table 6: Source of information regarding breastfeeding.}

\begin{tabular}{|lll|}
\hline Source & $\begin{array}{l}\text { Number of } \\
\text { cases }\end{array}$ & Percentage \\
\hline Health personals & 3 & $3.75 \%$ \\
\hline Family/friends & 40 & $50 \%$ \\
\hline Media/literature & 15 & $18.75 \%$ \\
\hline Previous experience & 20 & $25 \%$ \\
\hline None & 2 & $2.5 \%$ \\
\hline
\end{tabular}

Table 7: Knowledge regarding the breastfeeding.

\begin{tabular}{|c|c|c|c|c|}
\hline \multirow{2}{*}{$\begin{array}{l}\text { Sr. } \\
\text { No. }\end{array}$} & \multirow{2}{*}{ Responses } & \multirow{2}{*}{$\begin{array}{l}\text { Knows } \\
\%\end{array}$} & \multirow{2}{*}{$\begin{array}{l}\text { Does not } \\
\text { know } \\
\%\end{array}$} & \multirow{2}{*}{$\begin{array}{l}\text { Variable } \\
\text { response } \\
\%\end{array}$} \\
\hline & & & & \\
\hline 1 & $\begin{array}{l}\text { Knows that colostrum is the first breast milk, and may be watery in consistency } \\
\text { but is extremely crucial for the new born }\end{array}$ & $95 \%$ & $3.75 \%$ & $2.5 \%$ \\
\hline 2 & Recognizes that colostrum is important for the baby to maintain immunity & $97.5 \%$ & $1.25 \%$ & $1.25 \%$ \\
\hline 3 & $\begin{array}{l}\text { Exclusive breastfeeding implies giving no other feed to the baby other than breast } \\
\text { milk }\end{array}$ & $91.25 \%$ & $5 \%$ & $3.75 \%$ \\
\hline 4 & Is of the opinion that exclusive breast milk is completely adequate for newborns & $85 \%$ & $10 \%$ & $5 \%$ \\
\hline 5 & Knows Exclusive breastfeeding is for up to 6 months of age & $85 \%$ & $10 \%$ & $5 \%$ \\
\hline 6 & $\begin{array}{l}\text { Is aware that exclusive breastfeeding has numerous benefits for the baby like } \\
\text { prevention of diarrhea, other infections and protection from obesity and chronic } \\
\text { diseases of childhood etc. }\end{array}$ & $80 \%$ & $12.5 \%$ & $7.5 \%$ \\
\hline 7 & $\begin{array}{l}\text { Is aware that exclusive breastfeeding has numerous benefits for the mother like } \\
\text { delaying next pregnancy, losing the weight gained in pregnancy, protection from } \\
\text { various cancers etc. }\end{array}$ & $80 \%$ & $0 \%$ & $20 \%$ \\
\hline 8 & $\begin{array}{l}\text { Knows that Breastfeeding should be continued up to } 2 \text { years, and that } \\
\text { complementary feeds should accompany breast mild after } 6 \text { months of age }\end{array}$ & $87.5 \%$ & $7.5 \%$ & $5 \%$ \\
\hline 9 & $\begin{array}{l}\text { Aware that lactating mother must consume healthy, diversified diet, plenty of } \\
\text { water, for improving secretion of milk }\end{array}$ & $97.5 \%$ & $0 \%$ & $2.5 \%$ \\
\hline 10 & Knows that the baby should be fed on demand & $88.75 \%$ & $7.5 \%$ & $3.75 \%$ \\
\hline 11 & Knows the need to wash breast with warm water before each feed & $75 \%$ & $10 \%$ & $15 \%$ \\
\hline 12 & Knows to awaken baby while breastfeeding and burp after each feed & $90 \%$ & $6.25 \%$ & $3.75 \%$ \\
\hline 13 & $\begin{array}{l}\text { During breastfeeding mother must sit comfortably, should have eye to eye } \\
\text { contact with the baby and talk to the baby }\end{array}$ & $80 \%$ & $15 \%$ & $5 \%$ \\
\hline 14 & $\begin{array}{l}\text { In a situation of separation, the mother knows that breast milk should be } \\
\text { hygienically expressed, and that it can be stored up to } 4 \mathrm{hrs} \text { at room temperature, } \\
\text { post which refrigeration and thawing before feed would be needed }\end{array}$ & $60 \%$ & $12.5 \%$ & $80 \%$ \\
\hline 15 & $\begin{array}{l}\text { Seek professional help in case of difficulty in feeding, or the baby has diarrhea } \\
\text { etc., and knows that breastfeeding should not be discontinued at these times }\end{array}$ & $36.25 \%$ & $62.5 \%$ & $1.25 \%$ \\
\hline
\end{tabular}


Table 8: Knowledge scores of mothers in study.

\begin{tabular}{|lll|}
\hline $\begin{array}{l}\text { Knowledge score and } \\
\text { status }\end{array}$ & $\begin{array}{l}\text { Number of } \\
\text { mothers }\end{array}$ & Percentage \\
\hline 12 or more on 15-knows & 65 & $81.25 \%$ \\
\hline Less than 12 & 15 & $18.75 \%$ \\
\hline
\end{tabular}

\section{Attitude about breastfeeding}

In relation to attitudes of the mothers towards breastfeeding, the following percentage of participants agreed that breastfeeding was more beneficial than formula feeding- in terms of 1) nutrition- both long(18.75\%) and short term(97.5\%), 2) easy availability(92.5\%), 3) feeding technique $(82.5 \%), 4)$ digestibility $(90 \%)$ and 5) nascent establishment of the mother-infant bonding $(88.75 \%)$. Of the mothers, $95 \%$ accepted that formula feeding causes one to miss out on the great joys of motherhood and that breastfeeding caused no loss of figure as such (90\%). It was noted $66.25 \%$ of the mothers felt that "formula feeding is the better choice if the mother plans to go to work" and $65 \%$ of the participants agreed that the women can breastfeed in public places such as restaurants, religious places, etc. However, 65\% said that fathers felt they had no role to play in their child's nutrition if a mother breastfeeds. The popular fact that breastmilk is ideal for the babies was agreed by $97.5 \%$ of the mothers (Table 9).

Table 9: Attitude of mothers regarding breastfeeding.

\begin{tabular}{|llll|l|}
\hline Sr. & Response & Agree & Disagree & Neutral \\
\hline No. & & $\%$ & $\%$ & $\%$ \\
\hline $1^{*}$ & Believes that the benefit of breast milk lasts as long as baby is breast fed & $60 \%$ & $18.75 \%$ & $21.25 \%$ \\
\hline $2^{*}$ & Formula feed is more convenient than breastfeeding & $82.5 \%$ & $15 \%$ & $2.5 \%$ \\
\hline 3 & Breastfeeding increases mother infant bonding & $88.75 \%$ & $10 \%$ & $1.25 \%$ \\
\hline $4^{*}$ & Breast milk is lacking in iron & $35 \%$ & $60 \%$ & $5 \%$ \\
\hline 5 & Formula fed babies are likely to be fed more than breast fed babies & $93.75 \%$ & $3.75 \%$ & $2.5 \%$ \\
\hline $6^{*}$ & Formula feeding is better choice for women who go to work & $66.25 \%$ & $26.25 \%$ & $7.5 \%$ \\
\hline 7 & Mothers who formula feed miss the great joy of motherhood & $95 \%$ & $3.75 \%$ & $1.25 \%$ \\
\hline $8^{*}$ & Breastfeeding should be avoided in public places like restaurants, & $26.25 \%$ & $65 \%$ & $8.75 \%$ \\
\hline 9 & religious places & $95 \%$ & $5 \%$ & $0 \%$ \\
\hline $10 *$ & Freastfed babies are healthier than formulated babies & $65 \%$ & $20 \%$ & $15 \%$ \\
\hline 11 & Breast milk is ideal food & $97.5 \%$ & $2.5 \%$ & $0 \%$ \\
\hline 12 & Breast milk is more easily digested than formula feed & $90 \%$ & $7.5 \%$ & $2.5 \%$ \\
\hline $13 *$ & Formula feed is as healthy as breast milk for babies & $56.25 \%$ & $42.5 \%$ & $1.25 \%$ \\
\hline 14 & Breastfeeding is cheaper and more convenient than formula feed & $92.5 \%$ & $6.25 \%$ \\
\hline $15 *$ & Breastfeeding leads to loss of figure & $8.75 \%$ & $90 \%$ & $1.25 \%$ \\
\hline
\end{tabular}

*-Negatively worded questions

Table 10: Overall attitude of mother towards breastfeeding.

\begin{tabular}{|lll|}
\hline Attitude & $\begin{array}{l}\text { Number of } \\
\text { mothers }\end{array}$ & Percentage \\
\hline Positive to breastfeeding & 40 & $50 \%$ \\
\hline Neutral & 37 & $46.25 \%$ \\
\hline Positive to formula feeds & 3 & $3.75 \%$ \\
\hline
\end{tabular}

Each mother was grouped into either positive attitude to breastfeeding, neutral or positive attitude to formula feeds based on their responses. It was found that $50 \%$ of the mothers had a positive attitude towards breastfeeding, but an alarming $46.25 \%$ had a neutral attitude (Table 10 ).

\section{Practical aspects in early infant feeding}

Table 11 summarises breastfeeding practices among the study mothers. All mothers reported that they breastfed their new-borns, $31.25 \%$ of them had given prelacteal feeds- out of which $40 \%$ had given plain water and $20 \%$ were given sugared water. It was noted that $90 \%$ of the mothers had fed their new-borns with colostrums, $85 \%$ were prescribed galactagogues from postpartum day 2 . The study showed $93.75 \%$ of the mothers fed their newborns on demand and only $12.5 \%$ were intending to exclusively breastfeed their new-borns for less than 6 months. $2.5 \%$ have received lactation counselling (Table 11).

\section{Breastfeeding technique}

Breastfeeding hygiene, appropriate latching techniques and burping post feeds were followed by $81 \%-90 \%$ of the mothers, $62.5 \%$ mothers emptied one breast completely before feeding the baby from the other. It was seen that most mothers did not follow apt breastfeeding positions and releasing suction techniques while weaning off the baby from the breast (Table 12). 
Table 11: Early infant feeding practices.

\begin{tabular}{|llll|}
\hline \multirow{2}{*}{ Response } & & Number of cases & Percentage \\
\cline { 2 - 4 } & Given & 80 & $100 \%$ \\
\cline { 2 - 4 } Pre-lacteals & Not given & 0 & $0 \%$ \\
\hline \multirow{2}{*}{ Colostrum } & Given & 25 & $31.25 \%$ \\
\cline { 2 - 4 } & Not given & 55 & $68.75 \%$ \\
\hline \multirow{2}{*}{ Galactagogues } & Given & 72 & $90 \%$ \\
\cline { 2 - 4 } & Not given & 8 & $10 \%$ \\
\hline \multirow{2}{*}{ Timing of feed } & Used & 68 & $85 \%$ \\
\cline { 2 - 4 } & Not used & 12 & $15 \%$ \\
\hline \multirow{3}{*}{ Duration of intended exclusive breastfeeding } & On demand & 75 & $93.75 \%$ \\
\cline { 2 - 4 } & Scheduled & 5 & $12.5 \%$ \\
\cline { 2 - 4 } & Up to 3 months & 10 & $31.5 \%$ \\
\cline { 2 - 4 } $\begin{array}{l}\text { Has consulted a healthcare worker/has } \\
\text { received lactation counselling }\end{array}$ & Up to 1year & 25 & $6.25 \%$ \\
\cline { 2 - 4 } & $>1$ year & 5 & $2.5 \%$ \\
\cline { 2 - 4 } & Yes & 2 & $97.5 \%$ \\
\hline
\end{tabular}

Table 12: Technique of breastfeeding

\begin{tabular}{|lll|}
\hline Technique & Number of cases & Percentage \\
\hline Lying down while feeding & 25 & $31.25 \%$ \\
\hline Notices that the Nipple and areola are inside the mouth of the baby while it suckles & 70 & 87.5 \\
\hline Burps the baby after feeds & 74 & $92 \%$ \\
\hline Places fingers between nipple and areola to release suction & 2 & $2.5 \%$ \\
\hline Complete emptying of 1 breast before starting the other & 50 & $62.5 \%$ \\
\hline Knows the hygiene of breastfeeding and washes hand before feeding & 65 & $81.25 \%$ \\
\hline
\end{tabular}

\section{DISCUSSION}

Worldwide activities towards encouraging breastfeeding for maximal infant benefits has been emphasized since many centuries, however there is incongruence between the recommendations and real practices. Therefore, the present study aimed at identifying the KAP of breastfeeding among lactating mothers.

A total $43.75 \%$ of the mothers were educated and belonged to the upper middle class of the society. All the mothers included in the study were breastfeeding their babies.

A total $97.5 \%$ of the mothers were booked cases with routine ANC in study hospital, but the contribution of health personnel to their knowledge regarding breastfeeding was a petty $3 \%$. The supportive role played by family and friends in this aspect seemed to be significantly higher - 50\%. This shows that there is an urgent need to educate pregnant women and her family from early pregnancy itself regarding the significance and techniques of breastfeeding. Also, only $36.25 \%$ knew that they could approach healthcare professionals regarding breastfeeding difficulties. Only $2.5 \%$ have received lactation counselling. This portrays the insufficient role played by the healthcare workers in providing help to enforce the concept of breastfeeding. This may in the long run cause them to switch over to other feeds, turning out to be worrisome and hindering the accomplishment of the millennium development goals. ${ }^{6}$

Though $52.5 \%$ of the mothers delivered normally, only $47.5 \%$ of the mothers had initiated breastfeeding within an hour as per recommendations. ${ }^{7-9}$ Most common reason for delay in initiation of breastfeeding was cited as delay in shifting from labour room/ postoperative care or babies were in neonatal ICU. Sadly, $31.25 \%$ of these babies received prelacteal feeds which could be a source of contamination.

A total $95 \%-97 \%$ of them had good knowledge of the antibody rich colostrum and $90 \%$ of them provided these benefits to their newborns. $80 \%$ of them were aware of the concept of exclusive breastfeeding and only $12.5 \%$ were intending to exclusively breastfeed their newborn for less than 6 months.

Hygienic breastfeeding was known to $75 \%$ of the mothers and $81.25 \%$ of the mothers surprisingly adhered to it. $80 \%-91 \%$ of the mothers knew about the techniques of breastfeeding and most of them followed it appropriately. 
Yet like the other studies there seems to be some amount of perplexity regarding breastfeeding positions and suction releasing while weaning off the baby from the breast. ${ }^{10}$

A total $5 \%$ of the mothers under study were employed and $60 \%$ were familiar with the procedure, storage and usage of expressing breast feeds. With respect to the same, $66.25 \%$ of the mothers opined that formula feeds were the better choice for working mothers; and $95 \%$ agreed that mothers who formula feed miss the great joy of motherhood.

The present study shows that $81.25 \%$ of the mothers had good knowledge regarding breastfeeding, but the alarming finding was that $46.6 \%$ of them had a neutral attitude towards it. Though $65 \%$ of them agreed that they would not shy away from breastfeeding in public places, an equal number approved that the fathers felt no sense of responsibility towards the nutrition of a child who was breastfed.

\section{CONCLUSION}

Breastfeeding prevents approximately one-tenth of infant deaths and could play an imperative part in meeting India's millennium development goal of dipping child mortality. While the present study established the good knowledge, Indian mothers had regarding breastfeeding, it also uncovered the neutral attitudes they held towards it. This indicates that there is scope for improvement in breastfeeding practices with adequate and judicious attitude correction. The role that healthcare workers could play in this correction is very crucial. It is recommended that this could be done by simple supportive prenatal and postnatal counselling to the mother and her immediate family. This study recommends breastfeeding and peer support programs designed by healthcare workers to provide comprehensive knowledge that is tailored to the needs of pregnant women and lactating mothers to help increase breastfeeding initiation rates and boost breastfeeding practice. The findings of this study will be valuable to focus on behaviour change communication interventions, to improve breastfeeding and identify factors that influence its practice

\section{Funding: No funding sources} Conflict of interest: None declared

Ethical approval: The study was approved by the Institutional Ethics Committee

\section{REFERENCES}

1. Eidelman AI, Schanler RJ. Breastfeeding and the use of human milk. Pediatr. 2012;129(3):e827-41.

2. Ip S, Chung M, Raman G, Trikalinos TA, Lau J. A summary of the agency for healthcare research and quality's evidence report on breastfeeding in developed countries. Breastfeed Med. 2009;4 Suppl 1:S17-30.

3. Holme A, Macarthur, Christine Lancashire R. The effects of breastfeeding on cognitive and neurological development of children at 9 years. Child: Care, Health Develop. 2010;36:583.

4. Gupta, A, Dadhich JP, Faridi MMA. Breastfeeding and complementary feeding as a public health intervention for child survival in India. The Indian J Pediatr. 2010;77(4):413-8.

5. Issler H, Sá MBSRD, Senna DM. Knowledge of newborn healthcare among pregnant women: basis for promotional and educational programs on breastfeeding. Sao Paulo Med J. 2001;119(1):7-9.

6. Chandhiok N, Singh KJ, Sahu D, Singh L, Pandey A. Changes in exclusive breastfeeding practices and its determinants in India, 1992-2006: analysis of national survey data. Inter Breastfeed $\mathrm{J}$. 2015;10(1): 1 .

7. World health organization: Global strategy for infant and young child feeding, Geneva: World health organization; 2001: 1-5.

8. Baby friendly hospital initiative: UNICEF. Available at: https://www.unicef.org/nutrition/index_24806. html. Accessed on $11^{\text {th }}$ April 2020.

9. Banapurmath CR, Selvamuthukumaraswamy A. Breast feeding and first breast feed, correlation of initiation pattern and mode of delivery. Indian Paediatr. 1995;32:299-301.

10. Shrivastava SP, Sharma VK, Kumar V. Breast feeding pattern in a neonate. Indian Paediatr. 1994:31:1079-82.

Cite this article as: Pramodha MS, Pitty N, Chaitra $\mathrm{S}$. Knowledge, attitudes and practices of breast feeding among lactating mothers in a tertiary care hospital in Dakshina Kannada district: a crosssectional survey. Int J Reprod Contracept Obstet Gynecol 2020;9:3119-28. 


\section{Questionnaire}

\section{Annexure 1}

Consent for participation.

I , _ have been explained about the research titled- "Knowledge, attitudes and practices of breast feeding among lactating mothers in a tertiary care hospital in Dakshina Kannada district- a cross-sectional survey" and am willing to participate in it after completely understanding the objectives of the study, that has been explained to me in English/Kannada.

I know that this participation is completely voluntary, yields no reimbursements or deductions and that no participation will in no way harm my course of treatment in the hospital. I am aware that the details in the study will be published and that I have the right to withdraw from the study at any time.

Dated:

Sr. No.:

Name:

Age:

Religion Hindu/Muslim/Christian/Others

Highest educational status:

Employment status:

Pre-pregnancy weight (as per records)

Parity index

Booking status

Mode of delivery-Normal vaginal delivery/LSCS

Indication for LSCS

Immediate neonatal outcome (as per records)

How long were you separated from your newborn? (in hours)

Reason-

How did you know about the methods and significance of breastfeeding?

The following questions are to assess the knowledge that you have regarding breastfeeding

\begin{tabular}{|l|l|l|l|}
\hline Question & I know & I don't know & I am not sure \\
\hline Colostrum is the first breast milk, and may be watery in & & & \\
\hline
\end{tabular}


consistency but is extremely crucial for the new born

Colostrum is important for the baby to maintain immunity

Exclusive breastfeeding implies giving no other feed to the baby

other than breast milk

Exclusive breast milk is completely adequate for newborns

Knows Exclusive breastfeeding is for up to 6 months of age

Exclusive breastfeeding has numerous benefits for the baby like

prevention of diarrhea, other infections and protection from

obesity and chronic diseases of childhood etc.

Exclusive breastfeeding has numerous benefits for the mother

like delaying next pregnancy, losing the weight gained in

pregnancy, protection from various cancers etc.

Breastfeeding should be continued up to 2 Years, and that complementary feeds should accompany breast mild after 6 months of age

As a lactating mother, I must consume healthy, diversified diet, plenty of water, for improving secretion of milk

Knows that the baby should be fed on demand

Wash breast with warm water before each feed is important

Awaken baby while breastfeeding and burp after each feed

During breastfeeding I must sit comfortably, should have eye to

eye contact with my baby and talk to him/her

In a situation of separation, I know that breast milk should be hygienically expressed, and that it can be stored up to $4 \mathrm{hrs}$ at room temperature, post which refrigeration and thawing before feed would be needed

Will Seek professional help in case of difficulty in feeding, or the baby has diarrhea etc., and knows that breastfeeding should not be discontinued at these times

Total number of correct responses - knowledge score

\begin{tabular}{|c|c|c|c|c|c|}
\hline Questions & $\begin{array}{l}\text { Strongly } \\
\text { agree }\end{array}$ & Agree & Neutral & Disagree & $\begin{array}{l}\text { Strongly } \\
\text { disagree }\end{array}$ \\
\hline \multicolumn{6}{|l|}{$\begin{array}{l}\text { Believes that the benefit of breast milk lasts } \\
\text { as long as baby is breast fed }\end{array}$} \\
\hline \multicolumn{6}{|l|}{$\begin{array}{l}\text { Formula feed is more convenient than } \\
\text { breastfeeding }\end{array}$} \\
\hline \multicolumn{6}{|l|}{$\begin{array}{l}\text { Breastfeeding increases mother infant } \\
\text { bonding }\end{array}$} \\
\hline \multicolumn{6}{|l|}{ Breast milk is lacking in iron } \\
\hline \multicolumn{6}{|l|}{$\begin{array}{l}\text { Formula fed babies are likely to be fed more } \\
\text { than breast fed babies }\end{array}$} \\
\hline \multicolumn{6}{|l|}{$\begin{array}{l}\text { Formula feeding is better choice for women } \\
\text { who go to work }\end{array}$} \\
\hline \multicolumn{6}{|l|}{$\begin{array}{l}\text { Mothers who formula feed miss the great joy } \\
\text { of motherhood }\end{array}$} \\
\hline \multicolumn{6}{|l|}{$\begin{array}{l}\text { Breastfeeding should be avoided in public } \\
\text { places like restaurants, religious places }\end{array}$} \\
\hline \multicolumn{6}{|l|}{$\begin{array}{l}\text { Breastfed babies are healthier than } \\
\text { formulated babies }\end{array}$} \\
\hline \multicolumn{6}{|l|}{ Fathers feel left out if a mother breast feeds } \\
\hline \multicolumn{6}{|l|}{ Breast milk is ideal food } \\
\hline \multicolumn{6}{|l|}{$\begin{array}{l}\text { Breast milk is more easily digested than } \\
\text { formula feed }\end{array}$} \\
\hline \multicolumn{6}{|l|}{$\begin{array}{l}\text { Formula feed is as healthy as breast milk for } \\
\text { babies }\end{array}$} \\
\hline \multicolumn{6}{|l|}{$\begin{array}{l}\text { Breastfeeding is cheaper and more } \\
\text { convenient than formula feed }\end{array}$} \\
\hline Breastfeeding leads to loss of figure & & & & & \\
\hline
\end{tabular}




\begin{tabular}{|c|c|}
\hline \multicolumn{2}{|l|}{ Total number of appropriate responses - attitude score } \\
\hline \multirow[t]{2}{*}{ Do you breastfeed you baby? } & Given \\
\hline & Not given \\
\hline \multirow[t]{2}{*}{ Have you given your child any food/drink prior to breast milk? } & Given \\
\hline & Not given \\
\hline \multirow[t]{2}{*}{ Has your baby received colostrum? } & Given \\
\hline & Not given \\
\hline \multirow[t]{2}{*}{ Are you receiving any medication to increase breast milk? } & Used \\
\hline & Not used \\
\hline \multirow[t]{2}{*}{ How often do you feed your baby } & On demand \\
\hline & Scheduled \\
\hline \multirow[t]{4}{*}{ How long do you intend to exclusive breastfeed him/her? } & Up to 3 months \\
\hline & Up to 6 months \\
\hline & Up to 1 year \\
\hline & $>1$ year \\
\hline \multirow[t]{2}{*}{ Have you consulted any health care worker for lactation counselling } & Yes \\
\hline & No \\
\hline
\end{tabular}

\begin{tabular}{|l|l|l|}
\hline Technique & $\begin{array}{l}\text { Yes, I } \\
\text { follow it } \\
\text { this way }\end{array}$ & $\begin{array}{l}\text { No, I have not } \\
\text { been practicing } \\
\text { this way }\end{array}$ \\
\hline I Lay down while feeding him/her & & \\
\hline $\begin{array}{l}\text { I see to that my nipple and areola are inside the mouth of my baby while } \\
\text { he/she suckles }\end{array}$ & & \\
\hline I burp my baby after feeds & & \\
\hline I place my fingers between nipple and areola to release suction & & \\
\hline I Completely empty 1 breast before starting the other & & \\
\hline I hygiene of breastfeeding and washes hand before feeding & & \\
\hline
\end{tabular}

*******************************************************************

$\square \quad$ I have been educated regarding breastfeeding, its significance and techniques by the interviewer 